\title{
Farinha de Vísceras de Aves em Rações para a Tilápia do Nilo (Oreochromis niloticus L.) Durante a Fase de Reversão Sexual
}

\author{
Wilson Rogério Boscolo1*, Fábio Meurer ${ }^{2}$, Aldi Feiden $^{3}$, Carmino Hayashi $^{4}$, Adilson Reidel $^{5}$, \\ André Luis Genteline ${ }^{6}$
}

\begin{abstract}
RESUMO - Neste trabalho, objetivou-se avaliar o desempenho, a sobrevivência e a efetividade de reversão de larvas de tilápia do Nilo (Oreochromis niloticus L.) alimentadas com rações contendo níveis crescentes de inclusão de farinha de vísceras de aves (FVA). Utilizou-se 500 larvas de tilápia do Nilo com dois dias de idade, distribuídas em um delineamento inteiramente casualizado com cinco tratamentos e cinco repetições, sendo a unidade experimental constituída por um aquário de 30 L com 20 larvas. Foram elaboradas cinco rações com cinco níveis de inclusão de FVA ( $0 ; 20 ; 40,60 \%$ e 60\% mais lisina sintética). Foram elaboradas rações isocalóricas, isocálcicas, isofosfóricas e isoprotéicas, com $60 \mathrm{mg}$ de a-metiltestosterona $/ \mathrm{kg}, 38,6 \%$ de proteína digestível e 3.700 kcal de energia digestível/kg, de modo que a ração com inclusão de lisina foi isoaminoacídica para lisina em relação à ração sem a inclusão de FVA. O arraçoamento foi realizado quatro vezes ao dia, ad libitum. Ao final, foram avaliadas as médias de peso final (PF), comprimento total (CT), sobrevivência (SO) e efetividade de reversão (ER). Foi observado aumento linear no PF e CT com o aumento da inclusão da FVA na ração, enquanto, para SO, a ração sem FVA foi inferior às demais. As rações sem inclusão de FVA e com $20 \%$ de inclusão de lisina proporcionaram PF e CT médios inferiores e somente a ração sem FVA foi inferior para SO. Conclui-se que a FVA pode ser utilizada em rações para a tilápia do Nilo durante a reversão sexual.
\end{abstract}

Palavras-chave: farinha de vísceras de aves, nutrição de peixes, Oreochromis niloticus, tilápia do Nilo, reversão sexual

\section{Poultry Meal By-products in Diets for Nile Tilapia (Oreochromis niloticus L.) in the Reversion Phase}

\begin{abstract}
The objective of this work was to evaluate the performance, survival and effectiveness of reversion of Nile tilapia fry (Oreochromis niloticus L.) fed with rations containing growing levels of inclusion of poultry by products (FVA). Five hundred Nile tilapia fry were used with two days of age, allotted to a completely randomized design with five treatments and five replications, and the experimental unit an aquarium $30 \mathrm{~L}$ with 20 fry. Five rations were elaborated with levels of inclusion of FVA 0; 20; 40, 60\% and one of $60 \%$ of FVA plus synthetic lysine supplementation. The rations were isocalorics, isocalcics, isofosforics and isoproteic, with $60 \mathrm{mg}$ of a-metiltestosterona/ $\mathrm{kg}, 38.6 \%$ of digestible protein and $3700 \mathrm{kcal}$ of digestible energy/kg; the ration with lysine inclusion was isoaminoacidic for lysine in relation to the ration without inclusion of FVA. The ad libitum feeding was made four times a day. At the end of the experimental period, it was evaluated the final weight (PF), total length (CT), survival (SO) and reversion effectiveness (ER). A linear increase was observed for PF and CT with the increase of the inclusion of FVA in the ration. However, for SO the ration without FVA was inferior to the others.Rations without inclusion of FVA and with inclusion of $20 \%$ of lysine showed PF and CT medium inferiior and only the ration without FVA was inferior for SO. Concluding, FVA could be used in rations for the Nile tilapia during the sexual reversion.
\end{abstract}

Key Words: Oreochromis niloticus, poultry by products, Nile tilapia, nutrition of fish, sexual reversion

\section{Introdução}

A tilápia do Niloé uma espécie de grande importância dentro da piscicultura nacional, pois é de baixo nível trófico (onívora), o que a coloca em vantagem sobre as espécies carnívoras, que requerem grande quantidade de farinha de peixe nas rações (Fitzsimmons, 2000). Também aceita rações com grande facilidade desde o

\footnotetext{
1 Professor Adjunto do curso de Engenharia de Pesca, Universidade Estadual do Oeste do Paraná, Rua da Faculdade, 645, CEP: 85903-000, Toledo-Paraná, Brasil. GEMAq - Grupo de Estudos de Manejo na Aqüicultura. E.mail: wrboscolo@unioeste.br

2 Professor Assistente do curso de Medicina Veterinária PUCPR/Campus Toledo, Av. da União, 500, Jardim Coopagro, 85902-532, ToledoParaná; E.mail: fabiomeurer@pop.com.br

${ }^{3}$ Professor Adjunto do curso de Engenharia de Pesca, Universidade Estadual do Oeste do Paraná, Rua da Faculdade, 645, 85903-000, ToledoParaná, Brasil. E.mail: aldi@unioeste.br

${ }^{4}$ Biólogo; Centro Avançado de Pesquisa Tecnológica do Agronegócio de Pescado Continental, Instituto de Pesca, APTA/SAA, São José do Rio Preto/SP. E.mail: hayashi@pesca.sp.gov.br

5 Pós-graduando CAUNESP/UNESP, Via de Acesso Paulo Donato Castellani, s/n., Jaboticabal, São Paulo, Brasil; areidel@bol.com.br ${ }^{6}$ Acadêmico do curso de Engenharia de Pesca, Universidade Estadual do Oeste do Paraná.
} 
período larval (Meurer et al., 1999) e destaca-se em cultivos por apresentar crescimento rápido e grande rusticidade (Hayashi et al., 1999).

Com a difusão da aqüicultura, a demanda por rações para peixes e por seu principal ingrediente protéico, a farinha de peixe, está em franca expansão. A limitação do suprimento da farinha de peixe, decorrente da crescente demanda, gera a necessidade de se pesquisar fontes de proteína alternativas de boa qualidade nutricional (El-Sayed, 1999; Nengas et al., 1999).

O estudo de alimentos alternativos visa dar subsídios para a produção de rações, que, além de mais baratas e de mesma qualidade nutricional, proporcione desempenho produtivo semelhante ao daquelas formuladas com alimentos convencionais (Boscolo et al., 2002a; Meurer et al., 2003a). A farinha de vísceras de aves, da mesma maneira que a farinha de peixe, é um alimento de composição bastante variável e com alta porcentagem de cinzas (Hardy, 1996), pois depende da proporção de penas e de outras partes, como pés, cabeças, carcaças e restos de produção de filés.

Para a tilápia do Nilo, a farinha de víceras possui coeficiente de digestibilidade aparente de 82,03 e 72,09\%, respectivamente para a proteína e energia bruta, com valores de 47,65\% de proteína digestível e $3.651 \mathrm{kcal} / \mathrm{kg}$ e energia digestível, apresentando bom potencial para ser utilizada na formulação de rações para tilápias (Meurer et al., 2003a). A proteína da farinha de vísceras é deficiente nos aminoácidos treonina, fenilalanina e lisina (Kubitza, 1997) e não deve ser incluída em rações, em níveis acima de $20 \%$.

A nutrição na fase de reversão da tilápia é caracterizada por rações com alta densidade nutricional, contendo $38,6 \%$ de proteína digestível e $3.800 \mathrm{kcal} / \mathrm{kg}$ de energia digestível (Hayashi et al., 2002) e, ainda, hormônio masculinizante, quando na forma farelada (Meurer et al., 2003b). A fase de reversão sexual é de grande importância para o cultivo subseqüente, pois é responsável pelo fornecimento de alevinos em quantidade e qualidade adequada para o mercado consumidor.

O presente trabalho foi realizado com o objetivo de se avaliar o desempenho produtivo, efetividade da reversão sexual e a sobrevivência de larvas de tilápia do Nilo (Oreochromis niloticus, L.) durante o período de reversão sexual, alimentadas com rações contendo níveis crescentes de farinha de vísceras de aves com e sem inclusão de lisina sintética.

\section{Material e Métodos}

O experimento foi realizado no Laboratório de Aqüicultura da UNIOESTE/Toledo e teve duração de 28 dias. Foram utilizadas 500 larvas de tilápia do Nilo com dois dias de idade, distribuídas em um delineamento inteiramente casualizado, com cinco tratamentos e cinco repetições, sendo a unidade experimental composta por um aquário de $30 \mathrm{~L}$ contendo 20 larvas.

Os aquários possuíam aeração constante, por meio de pedras microporosas ligadas a um soprador, e foram sifonados diariamente de manhã e à tarde, de modo que, durante os 14 primeiros dias, foram retirados $25 \%$ e, nos 14 dias posteriores, $50 \%$ da água. Os parâmetros físico-químicos da água - $\mathrm{pH}$, condutividade elétrica $(\mu \mathrm{S} / \mathrm{cm})$ e oxigênio dissolvido $(\mathrm{mg} / \mathrm{L})$ - foram mensurados semanalmente, enquanto a temperatura $\left({ }^{\circ} \mathrm{C}\right)$ foi monitorada diariamente, de manhã $(8 \mathrm{~h})$ e à tarde (16h30), sempre antes da sifonagem.

Os tratamentos foram constituídos por cinco rações, com quatro níveis de inclusão de farinha de vísceras de aves $(0,00 ; 20,00 ; 40,00,60,00 \%)$ e uma com $60 \%$ de inclusão da farinha de aves (FVA), porém com adição de lisina sintética (L-lisina $\mathrm{HCl}$, 49\% de lisina), de maneira a ficar isoaminoacídica para este aminoácido com a ração controle à base de farinha de peixe e farelo de soja (0,00\% FVA). A farinha de vísceras de aves foi adquirida de um abatedouro de frangos e foi composta por vísceras e frangos descartados, sem adição de penas, contendo $58,11 \%$ de $\mathrm{PB}$, enquanto a farinha de peixe foi elaborada com resíduos da indústria de processamento de peixes de origem marinha e continha $58,9 \%$ de $\mathrm{PB}$ e coeficientes de digestibilidade aparente determinados por Meurer et al. (2003a). As rações experimentais foram formuladas de modo a serem isocalóricas, isocálcicas, isofosfóricas e isoprotéicas (Tabela 1).

Para a fabricação das rações os alimentos (farelo de soja, milho, farinha de peixes e farinha de vísceras de aves) foram moídos em triturador com peneira de $0,5 \mathrm{~mm}$ e posteriormente misturados. Após homogeneização, foram adicionados $60 \mathrm{mg}$ do hormônio a-metiltestosterona/kg em cada ração, de acordo com Hayashi (1995). As rações foram fornecidas à vontade quatro vezes ao dia, às $9 \mathrm{~h}, 11 \mathrm{~h} 30,14 \mathrm{~h}$ e $17 \mathrm{~h}$.

Ao final do período experimental, todos os animais das unidades experimentais foram contados, medidos e pesados individualmente, para avaliar o peso final médio $(\mathrm{g})$, a sobrevivência (\%) e o comprimento total 
Tabela 1- Composição percentual e química das rações experimentais com diferentes níveis de inclusão de farinha de vísceras de aves, utilizadas para larvas de tilápia do Nilo (matéria natural) ${ }^{1}$

Table 1 - Percent and chemical composition of the experimental rations with different levels of poultry by-products fed to Nile tilapia larvae (as fed basis) ${ }^{1}$

\begin{tabular}{|c|c|c|c|c|c|}
\hline \multirow[t]{2}{*}{$\begin{array}{l}\text { Alimento }(\%) \\
\text { Food }\end{array}$} & \multicolumn{5}{|c|}{$\begin{array}{c}\text { Nível de inclusão (\%) } \\
\text { Inclusion level }\end{array}$} \\
\hline & 0 & 20 & 40 & 60 & $60 *$ \\
\hline Calcário calcítico (Limestone) & - & 0,70 & 1,40 & 2,10 & 2,06 \\
\hline Fosfato bicálcico (Dicalcium phosphate) & - & 1,12 & 2,25 & 3,37 & 3,47 \\
\hline Farelo de soja (Soybean meal) & 38,75 & 31,81 & 24,87 & 17,92 & 13,66 \\
\hline Farinha de peixe (Fish meal) & 40,59 & 27,06 & 13,53 & - & - \\
\hline Milho (Corn) & 10,22 & 8,77 & 7,31 & 5,86 & 7,23 \\
\hline Óleo vegetal (Vegetal oil) & 8,91 & 9,02 & 9,13 & 9,24 & 10,28 \\
\hline Premix $^{1}$ (Supplement) & 1,00 & 1,00 & 1,00 & 1,00 & 1,00 \\
\hline $\mathrm{NaCl}$ & 0,50 & 0,50 & 0,50 & 0,50 & 0,50 \\
\hline Fibra bruta (Crude fiber) & 2,09 & 1,72 & 1,35 & 0,99 & 0,81 \\
\hline Cálcio(Calcium) & 2,91 & 2,91 & 2,91 & 2,91 & 2,91 \\
\hline Fósforo (Phosphorus) & 1,50 & 1,50 & 1,50 & 1,50 & 1,50 \\
\hline Extrato etéreo (Ether extract) & 17,07 & 18,79 & 20,51 & 22,23 & 23,22 \\
\hline Ácido linoléico (Linoleic acid) & 5,33 & 5,98 & 6,62 & 7,27 & 7,83 \\
\hline Metionina+Cistina $($ Met + Cys $)$ & 1,85 & 1,84 & 1,82 & 1,81 & 1,75 \\
\hline Lisina (Lysine) & 3,36 & 2,94 & 2,51 & 2,09 & 3,36 \\
\hline Proteína bruta (Crude protein) & 42,83 & 43,15 & 43,46 & 43,77 & 43,57 \\
\hline
\end{tabular}

*Ração com suplementação de lisina (Lysine suplementation diet).

${ }_{1}^{1}$ Níveis de garantia por quilograma do produto (Rovimix peixes): Vit. A, 500.000 UI; Vit. $D_{3}, 200.000$ UI; Vit. E, 5.000 mg; Vit. K3, $1.000 \mathrm{mg}$; Vit. B1, $1.500 \mathrm{mg}$; Vit. B2, $1.500 \mathrm{mg}$; Vit. B6, $1.500 \mathrm{mg}$; Vit. B12, $4.000 \mathrm{mg}$; Ác. Fólico, $500 \mathrm{mg} ;$ Pantotenato Ca, $4.000 \mathrm{mg} ;$ Vit. C, 15.000 mg; Biotina, 50 mg; Inositol, 10.000; Nicotinamida, 7.000; Colina, 40.000 mg; Co, 10mg; Cu, 500 mg; Fe, 5.000mg; I, 50 mg; Mn, $1500 \mathrm{mg}$; Se, $10 \mathrm{mg} ; \mathrm{Zn}, 5.000 \mathrm{mg}$.

1 uarantee levels for kilogram of product (Rovimix peixes): Vit. A, $500.000 \mathrm{UI}$; Vit. D, $200.000 \mathrm{UI}$; Vit. E, $5.000 \mathrm{mg}$; Vit. K3, $1.000 \mathrm{mg}$; Vit. B1, $1.500 \mathrm{mg}$; Vit. B2, 1.500 mg; Vit. B6, 1.500 mg; Vit. B12, 4.000 mg; Folic acid, 500 mg; Pantonthenic calcium, 4.000 mg; Vit. C, 15.000 mg; Biotin, 50 mg; Inositol, 10.000 ; Nicotinamide, 7.000; Choline, $40.000 \mathrm{mg}$; Co, $10 \mathrm{mg}$; Cu, 500mg; Fe, $5.000 \mathrm{mg}$; I, 50mg; Mn, $1500 \mathrm{mg}$; Se, $10 \mathrm{mg} ; \mathrm{Zn}, 5.000 \mathrm{mg}$.

2 Exigência nutricional baseada no NRC (1993) e Hayashi et al. (2002). Baseados nos valores de energia e proteína digestíveis propostos por Boscolo et al. (2002b) e Meurer et al. (2003a).

2 Nutritional requirements based on NRC (1993) and Hayashi et al. (2002). Digestible energy and protein based in Boscolo et al. (2002b), Meurer et al. (2003a)

médio $(\mathrm{cm})$. Posteriormente, os peixes foram sacrificados e fixados em formalina (10\%) para a avaliação da efetividade de reversão sexual, de acordo com a metodologia descrita por Popma \& Green (1990).

Os dados coletados foram submetidos à análise de variância a 5\% de probabilidade e, em caso de diferença estatística, foram aplicados a análise de regressão e o teste de média, utilizando-se o programa computacional SAEG - Sistema de Análises Estatísticas e Genéticas (UFV, 1997).

\section{Resultados e Discussão}

Os parâmetros físico-químicos da água dos aquários experimentais não apresentaram diferenças significativas $(\mathrm{P}>0,05)$ entre os tratamentos. As médias de temperatura, condutividade, oxigênio dissolvido e $\mathrm{pH}$, durante o período experimental, foram de $26,78 \pm 0,36^{\circ} \mathrm{C} ; 76,89 \pm 1,16 \mu \mathrm{S} / \mathrm{cm} ; 3,65 \pm 0,36 \mathrm{mg} / \mathrm{L} \mathrm{e}$ $6,87 \pm 0,29$, respectivamente, permanecendo dentro dos níveis recomendados para a espécie (Boyd, 1990; Popma \& Phelps, 1998).

Constam, na Tabela 2, os valores finais médios de peso, comprimento, sobrevivência e efetividade de reversão de larvas de tilápia do Nilo alimentadas com rações com níveis crescentes de FVA e ração com suplementação de lisina.

Os resultados de peso e comprimento finais médios apresentados pelos alevinos de tilápia do Nilo ao final do período de reversão sexual, para as rações sem o aminoácido sintético, apresentaram aumento linear $(\mathrm{P}<0,05)$ em função da inclusão da FVA. Para 
Tabela 2 - Valores médios de desempenho de larvas de tilápia do Nilo durante a fase de reversão sexual, alimentadas com diferentes níveis de farinha de vísceras de aves, com ou sem suplementação de lisina

Table 2 - Average of performance values of Nile tilapia during sex revertion phase fed diets with different levels of poultry by-products meal with or without lysine suplementation

\begin{tabular}{|c|c|c|c|c|c|c|}
\hline \multirow[t]{2}{*}{$\begin{array}{l}\text { Variável } \\
\text { Variable }\end{array}$} & \multicolumn{5}{|c|}{$\begin{array}{l}\text { Nível de inclusão de farinha de vísceras de aves } \\
\text { Poultry meal by-products level inclusion }\end{array}$} & \multirow[t]{2}{*}{$\mathrm{CV}$} \\
\hline & 0,00 & 20,00 & 40,00 & 60,00 & $60,00+$ Lis & \\
\hline Peso final $^{1}(\mathrm{~g})$ & $0,51 \mathrm{~b}$ & $0,59 b$ & $0,76 \mathrm{a}$ & $0,75 \mathrm{a}$ & $0,72 \mathrm{a}$ & 54,67 \\
\hline $\begin{array}{l}\text { Final weight } \\
\text { Comprimento final }{ }^{2}(\mathrm{~mm}) \\
\text { Final length }\end{array}$ & $28,90 \mathrm{~b}$ & $30,80 \mathrm{~b}$ & $33,20 \mathrm{a}$ & $33,40 \mathrm{a}$ & $33,10 \mathrm{a}$ & 19,29 \\
\hline $\begin{array}{l}\text { Sobrevivência }(\%) \\
\text { Survival rate }\end{array}$ & $50,00 \mathrm{~b}$ & $91,00 \mathrm{a}$ & $84,00 \mathrm{a}$ & $85,00 \mathrm{a}$ & $92,00 \mathrm{a}$ & 21,39 \\
\hline $\begin{array}{l}\text { Efetividade de reversão (\%) } \\
\text { Reversion efficiency }\end{array}$ & 100,00 & 100,00 & 100,00 & 100,00 & 100,00 & 0,00 \\
\hline
\end{tabular}

Médias na mesma linha seguidas de letras distintas diferem $(P<0,05)$ pelo teste Duncan.

Averages in the same line followed by distinct letters differ $(P<.05)$ by Duncan test.

${ }^{1} \mathrm{Y}=0,519888+0,00443326 \mathrm{X}, \mathrm{r}^{2}=0,85 .{ }^{2} \mathrm{Y}=29,3144+7,73107 \mathrm{X}, \mathrm{r}^{2}=0,91$. Regressão feita com os tratamentos 0,$00 ; 20,00 ; 40,00$ e $60,00 \%$ (regression performed for the treatments .00; 20.00, 40.00, and 60.00\%).

este mesmo parâmetro, a inclusão de lisina sintética promoveu resultados semelhantes ao dos tratamentos com 40 e $60 \%$ de inclusão de FVA, sendo superior aos demais tratamentos $(\mathrm{P}<0,05)$.

A sobrevivência foi afetada pela inclusão da FVA, pois o valor deste parâmetro para a ração sem inclusão de FVA foi inferior $(\mathrm{P}<0,05)$ ao dos demais tratamentos, que foram semelhantes entre si. A efetividade da reversão sexual não foi afetada $(\mathrm{P}>0,05)$ pela inclusão da FVA.

Os valores de desempenho deste experimento diferem dos obtidos por Quartararo et al. (1998), que observaram redução no ganho de peso dos peixes alimentados com níveis de inclusão de FVA acima de $20 \%$ em rações para o Pagrus auratus. A farinha de vísceras de aves utilizada por esses autores continha $60,3 \%$ proteína bruta em substituição a farinha de peixe com $72,9 \%$ de proteína bruta, que foi superior à utilizada neste experimento, ou seja, farinha de peixe de excelente qualidade segundo Hardy (1996). Porém, corroboram parcialmente os resultados de Webster et al. (1999), que, estudando alimentos alternativos à farinha de peixes para o sunshine bass (Morone chrysops x M. saxatilis), constataram que pode-se incluir até $28 \%$ de FVA sem reduzir o ganho de peso e modificar a composição da carcaça dos animais. Resultados semelhantes aos obtidos neste ensaio foram registrados por Faria et al. (2002), que avaliaram a inclusão de $0,4,8,12,16$ e $20 \%$ de inclusão de FVA em rações para alevinos de tilápia do
Nilo e verificaram aumento linear $(\mathrm{P}<0,05)$ na percentagem de ganho de peso dos animais.

O melhor desempenho observado com maiores inclusões de FVA pode estar relacionado ao aumento linear da quantidade de lipídeos e à diminuição da quantidade de amido nas rações (Tabela 01), resultantes da diminuição dos níveis de milho e farelo de soja na ração, o que pode ter decorrido da menor capacidade no aproveitamento do amido em relação aos lipídeos, como fonte de energia, por tilápias do Nilo na fase de revesão sexual (Hayashi et al., 2003).

Esses resultados demonstram que a FVA foi um bom substituto da farinha de peixe, entretanto deve ser ressaltada sua ótima qualidade, uma vez que foi fabricada sem a adição de penas, enquanto a farinha de peixes foi uma farinha de peixes nacional, formulada a partir dos resíduos do processamento de pescado. Outro fator que deve ser destacado é que não há necessidade da inclusão da lisina sintética nas rações com inclusão de farinha de vísceras e que, a partir da inclusão de $40 \%$ de FVA, os valores de desempenho permanecem semelhantes. Segundo recomendações de Santiago \& Lovell (1988), citados pelo NRC (1993), a exigência de lisina em rações para juvenis de tilápia do Nilo é de $5,12 \%$ da proteína total ou 1,43\% da ração. Se considerarmos $5,16 \%$ da proteína total, a ração com $60 \%$ de FVA deveria conter 2,24\%, nível que não foi atingido na ração com $60 \%$ de inclusão de FVA sem a suplementação de lisina sintética (Tabela 1), e esta ração proporcionou excelente desempenho às 
tilápias na fase inicial, que são mais exigentes que juvenis (Hayashi et al., 2002). No entanto, os resultados experimentais indicam que a lisina não foi limitante, e, portanto, não é necessária sua suplementação, quando feita a inclusão de FVA.

\section{Conclusões}

A farinha de vísceras de aves pode ser utilizada como fonte protéica para alevinos de tilápia do Nilo na fase de reversão sexual.

\section{Literatura Citada}

BOSCOLO, W.R.; HAYASHI, C.; MEURER, F. Farinha de Varredura de mandioca (Manihot esculenta) na alimentação de alevinos de Tilápia do Nilo (Oreochromis niloticus L.). Revista Brasileira de Zootecnia, v.13, n.2, p.545-551, 2002a.

BOSCOLO, W.R.; HAYASHI, C.; MEURER, F. Digestibilidade aparente da energia e nutrientes de alimentos convencionais e alternativos para a Tilápia do Nilo (Oreochromis niloticus, L.). Revista Brasileira de Zootecnia, v.13, n.2, p.539-545, 2002b.

BOYD, C. Water quality in ponds for aquaculture. London: Birmingham Publishing Co, 1990. 482p.

EL-SAYED, A.F.M. Alternative dietary protein sources for farmed tilapia, Oreochromis spp. Aquaculture, v.179, p.149-168, 1999.

FARIA, A.C.E.A.; HAYASHI, C.; SOARES, C.M. Farinha de vísceras de aves em rações para alevinos de tilápias do Nilo Oreochromis niloticus (L.). Revista Brasileira de Zootecnia, v.31, n.2, p.812-822, 2002.

FITZSIMMONS, K. Tilapia: most important aquaculture species of the $21^{\text {st }}$ century. In: PROCEEDINGS FROM THE FIFTH INTERNATIONAL SYMPOSIUM ON TILAPIA AQUACULTURE, 2000, Rio de Janeiro. Anais... Rio de Janeiro: ISTA, 2000. p.3-8.

HARDY, R.W. Alternate protein sources for salmon and trout diets. Animal Feed Science Technology, v.59, p.71-80, 1996.

HAYASHI, C. Breves considerações sobre as tilápias. In: RIBEIRO, R.P.; HAYASHI, C; FURUYA, W.M. (Eds.). Curso de piscicultura - criação racional de tilápias. 1.ed. Maringá: Eduem, 1995. p.4.

HAYASHI, C.; BOSCOLO, W.R.; SOARES, C.M. et al. Uso de diferentes graus de moagem dos ingredientes em dietas para a tilápia do Nilo (Oreochromis niloticus L.) na fase de crescimento. Acta Scientiarum, v.21, n.3 p.733-737, 1999.

HAYASHI, C.; BOSCOLO, W.R.; SOARES, C.M. et al. Exigência de proteína digestível para larvas de tilápia do Nilo (Oreochromis niloticus) durante a reversão sexual. Revista Brasileira de Zootecnia, v.31, n.2, p.823-828, 2002.
HAYASHI, C.; BARBERO, L.M.; MEURER, F. et al. Farelo de soja para a tilápia do Nilo (Oerechromis niloticus) durante a fase de reversão sexual. In: REUNIÃO ANUAL DA SOCIEDADE BRASILEIRA DE ZOOTECNIA, 40., 2003, Santa Maria. Anais... Santa Maria: Sociedade Brasileira de Zootecnia, [2003]. CD-ROM.

KUBITZA, F. Nutrição e alimentação dos peixes. Piracicaba: ISBN, 1997. 74p.

MEURER, F.; HAYASHI, C.; BOSCOLO, W.R. Influência do processamento da ração no desempenho e sobrevivência da tilápia do Nilo durante a reversão sexual. Revista Brasileira de Zootecnia, v.32, n.2, p.262-267, 2003b.

MEURER, F.; HAYASHI, C.; BOSCOLO, W.R. Digestibilidade aparente de alguns alimentos protéicos pela tilápia do Nilo (Oreochromis niloticus). Revista Brasileira de Zootecnia, v.32, n.6, 2003a.

MEURER, F.; HAYASHI, C.; SOARES, C. M., et al. Níveis de gordura na alimentação de machos de tilápia do Nilo (Oreochromis niloticus, L.), revertidos sexualmente, na fase inicial. In: ACUICULTURA VENEZUELA, 1999, Puerto La Cruz, Venezuela. Anais... Puerto La Cruz, Venezuela: ASA, 1999. p.348-357.

NATIONAL RESEARCH COUNCIL - NRC. Nutrient requirements of warmwater, fishes and shellfishes: nutrient requirements of domestics animals. Washington, D.C.: 1993. 114p.

NENGAS, I.; ALEXIS, M.N.; DAVIES, S.J. High inclusion levels of poultry meal and related byproducts in diets for gilthead seabream Sparus auratas L. Aquaculture, v.179, p.13-33. 1999.

POPMA, T.J.; GREEN, B.W. Aquaculture production manual - Sex reversal of tilapia in earth ponds. Research and Development Series no35. Alabama: Auburn University, 1990. 15p.

POPMA, T.J.; PHELPS, R.P. Status report to commercial tilápia producers on monosex fingerling productions techniques. In: SIMPÓSIO SUL AMERICANO DE AQUICULTURA, 1., 1998, Recife. Anais... Florianópolis: SIMBRAQ, 1998. p.127.

QUARTARARO, N.; ALLAN, G.L.; BELL, J.D. Replacement of fish meal in diets for Australian snapper, Pagrus auratus. Aquaculture, v.166, p.279-295, 1998.

UNIVERSIDADE FEDERAL DE VIÇOSA - UFV. Sistema para análises estatísticas e genéticas - SAEG. Versão 7.1. Viçosa, MG, 1997. 150p. (Manual do usuário).

WEBSTER C.D.; TIU, L.G.; MORGAN, A.M. et al. Effect of partial and total replacement of fish meal on growth and body composition of sunshine bass Morone chrysops $\mathrm{x}$ M. saxatilis fed practical diets. Journal of the World Aquaculture Society, v.30, n.4, p.443-453, 1999.

Recebido em: 17/02/04 Aceito em: 10/03/05 